\title{
EMPIRICAL EXPERIENCE ON COMBINING AHP WITH NON-AHP DECISION MODELS IN MANAGING CROSS FUNCTIONAL CONFLICTS
}

\author{
Kadarsah Suryadi \\ Laboratory of Information System and Decision Making \\ Industrial Management Research Group \\ Department of Industrial Engineering - Bandung Institute of Technology \\ Jl. Ganesa 10 Bandung, Tel./fax:62-22-2508141 \\ kadarsah@bdg.centrin.net id
}

Key words: AHP, empirical experience, Non-AHP, cross functional conflict, organizational need

Summary: This paper proposes an empirical experience corresponding to combination between AHP and some decision models. The later consists of AHP derivations and non-AHP models. Main objective of this combination model is to provide a decision support for an industrial system to manage cross functional conflicts. In fact, different functions in an organization have different interests, and this lead to conflicting factors between organizational functions. The proposed model tried to compromize the conflicts by defining strategic goals and its relevant criteria. The criteria represent key success factors of inconflict functions. By the aid of the proposed model, all decision makers can prioritize actions which are best fit to organizational needs, not to functional needs.

\section{Introduction}

Decision makers and managers in the last two decades have witnessed a period of change unparalleled in the history of the world, in terms of advances in technology, globalization of markets, and stabilization of political economies. With the increasing number of "world class" competitors both domestically and abroad, organizations have had to improve their internal processes rapidly in order to stay competitive. When companies began to develop detailed market strategies, they focused on creating and capturing customer loyalty. Organizations also realized that strong engineering, design, and manufacturing functions were necessary in order to support these market requirements. Design engineers had to be able to translate customer needs into product and service specifications, which then had to be produced at a high level of quality and at a reasonable cost.

As the demand for new products escalated, manufacturing organizations were required to become inceasingly flexible and responsive to modify existing products and processes or to develop new ones in order to meet ever-changing customer needs. As manufacturing capabalities improved, decision makers and managers realized that material and service inputs from suppliers had a major impact on their organization's ability to meet customer needs. This led to an increased focus on the supply base and the organization's sourcing strategy. It was realized that producing a quality product wast not enough. Getting the products to customers when, where, how, and in the quantity that they want, in a cost-effective manner, constituted an entirely new type of challenge. 
Three main aspects, i.e.: better quality, low cost and fast lead time, are needed by customers. To satisfy this growing need, the industry has to improve its competitive advantage. One of strategic aspects in industrial management is how compromized these three aspects. Often, companies envisage cross functional conflict in order to satisfy their customers. For example: production unit want to deliver their products on time. But to make on time product delivery, it necessites on time raw material supply. On the other hand, on time material supply needs best service level from inventory unit, whereas one of key success factors in inventory unit is how to minimize inventory cost in certain periode. In this case, production unit needs raw material supply with infinite quantity, while inventory unit needs to supply finite quantity of raw material. Other problem arises when production unit needs that all machines run during production periodes. In this case, maintenance unit has predicted maintenance program, where some machines have to be repaired. Maintenance activities correspond to spare part and material supply from inventory unit. Again, inventory unit has relation with maintenance unit, in which spare parts must be provided on time to support maintenance program. Getting material supply for fulfilling the needs of production and maintenance units will influence procurement and budgeting activities. In fact, logistic unit has limited budget to execute material procurement program, meanwhile inventory unit need material supply regardless financial constraints. So, companies have cross functional conflicts, and it needs to define decision model to compromize these decision criteria among conflicting functions.

\section{Objectives}

The proposed research has objectives to:

a. Identify decision criteria related to cross functional conflict

b. Formulate mechanisme of compromizing cross functional conflicts

c. Developing weighting model for decision makers involving in cross functional conflict

d. Developing mechanism of alternatives evaluation through specific authorization of decision maker

\section{Model Development}

\subsection{Cross Functional Conflicts}

To simplify modeling process, the proposed research is limited on spare part material management system. In fact, spare part availibility is one of most critical component in operation sustainability.

Functions related to spare parts management are:
a. Operation
b. Maintenance
c. Inventory
d. Procurement

The following is description of each function point of view concerning spare part material management.

\section{Operation Function Point of View}

To run production or operation activites, company needs many kind of technology, facilities, and equipments. Operation function must ensure their production sustainability to support product delivery commitment to their customers. Key success factors in operation function concern product and process quality, minimal process lead time, minimal production cost, 
high efficiency and productivity, machine reliability, machine availability, process flexibility, design consistency, etc. In order to achieve these factors, operation activities need support of spare parts supply. This spare parts supply is expected to be on time, high quality, right quantity such that operation runs without disruption caused by spare parts handling problem.

\section{Maintenance Function Point of View}

Role of maintenance unit is to ensure that all operation machines are available and reliable. The maintenance activities concern preventive maintenance, overhaul and divers repair works. This unit has key success factors, such as: on time maintenance schedule and implementation, ensuring minimal machines breakdown, increasing machine availability, increasing machine reliability, etc. All of these key succes factors are influenced by spare part availability. Maintenance unit often needs supply of sparepart materials regardless its budget constraints. The most important for the maintenance unit is all required spareparts are available on time, in right quantity and on required specifications.

\section{Inventory Function Point of View}

In the reality, inventory management system envisages choices to stock or not stock materials needed to support its operational activities. When the a decision maker decide to stock materials, there will be some risks concerning warehousing space, holding cost, opportunity cost, related technical aspects, etc. When the decision maker decide not to stock, there also will be many "sacryfices" to do, such as out of stock, production and distribution delay, penalty cost due to product delivery delay, etc. When materials to stock are in small volume, and in small price, financial risk is not too important. But when the material volume is large, and in a high price, so company will envisage a major risks, especially those related to holding cost when the materials are stocked in a long period.

\section{Procurement Function Point of View}

Procurement process consists of preparation and negotiation.

Preparation process corresponds to the following activities:

- identify needs, such as dependability, long term availability

- evaluate user requirements to ensure suitability of purchase

- forecast when and how purchase will be needed

- identify and select suppliers

- develop an efficient ordering system for control

Negotiation process consists of:

- bidding processes

- contracts

Meanwhile procurement function envisages supply uncertainty, such as:

- lead time to supply

- quantity supplied

- quality of supply

- data accuracy on products supplied and prices.

Based on above description, we can identify some key success factors in procurement function: certainty of spare parts requirement, supplier performances, delivery lead time from vendor to company, vendor availability.

The key success factors of all above functions become contradictory imperatives. For example, in operation function, to support operational sustainability, "contribution to production continuity" is main criteria to provide spare parts. The consequence is: inventory function has to stock spare parts, in maximum quantity to support operation sustainability. This is contradictory with inventory philosopy where decision criterium is how "to minimize 
stock quantity", while operation decision criterium is "how to provide spare parts material in unlimited number”.

\subsection{How to minimize cross functional conflicts}

This research proposes a framework for minimizing cross functional conlflicts in spare parts procurement decision making, using the following steps:

Step 1: Identifying list of functions related to spare parts procurement decision making

Step 2: Identifying list of criteria necessary for spare parts procurement decision making

Step 3: Mapping relationship between criteria versus functions (Tabel 1)

Step 4: Building decision tree (objective: priority of spare parts procurement)

Step 5: Weighting criteria

Step 6: Weighting spare parts priority (based on decision criteria versus related functions, as shown in Table 1)

Step 7: Listing spare parts procurement priority

\section{Step 1: Identify list of functions related to spare parts procurement decision making}

This step is based on Nominal Group Technique (NGT) forum and using "Functional Context Diagram”

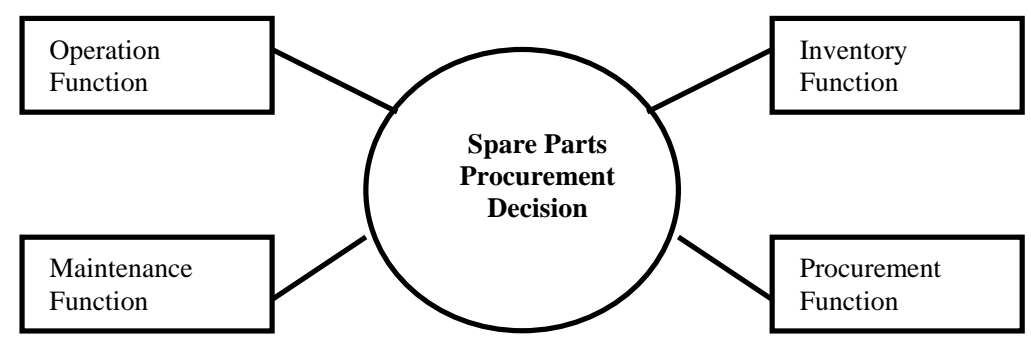

Figure 1- Functional Context Diagram"

Empirically, according to NGT forum in five manufacturing companies, there are four functions that have strong relationship with spare parts procurement decision making activities, i.e.: Operation, Inventory, Maintenance and Procurement. In this case, financial function is automacally related to spare parts procurement and many other activities in the companies. That's why financial function is not shown in the functional context diagram.

\section{Step 2: Identify list of criteria necessary for spare parts procurement decision making}

This list is completed by professional staff members of functions involved in spare part/material usage: Operation Unit, Inventory Unit, Procurement Unit and Maintenance functions. Again, this step is conducted through NGT forum, and first round of this step has resulted 17 criteria candidates. These criteria candidates then analysed using Cut Off Point technique proposed by [Tam \& al. 2001]. In order to class this list in descending order of relevance, the research conducts a survey involving staff members selected from the four functions who are directly involved in the material/spare parts selection process. It has been chosen to give them a questionnaire in which they will have to give a mark to each criteria. They will use the three-point scale of "not important", "somewhat important" and "very important" using "Cut off Point” approach as developped by [Tam \& al. 2001]. Its result consists of nine selected criteria, as shown in Tabel 1.

\section{Step 3: Mapping relationship between criteria versus functions}


After determining list of selected criteria, the next step is to map relationship between criteria and related functions. Each function is considered to be in charge of related criteria. That's why, during spare part procurement priority weighting, people who is responsible of each function has important role in evaluating spare part priority based on associated criteria. For example, decision maker in operation function has responsible in evaluating spare parts procurement priority according to criterium "contribution to production continuity" (see Tabel 1).

Tabel 1 Decision Criteria in Spare Parts Management

\begin{tabular}{|l|l|l|l|l|}
\hline $\begin{array}{l}\text { Related } \\
\text { Functions }\end{array}$ & Operation & Maintenance & Inventory & Procurement \\
\hline $\mathbf{C}$ Criteria & & & & \\
\hline $\begin{array}{l}\text { Spare Part Delivery } \\
\text { Lead Time }\end{array}$ & & & & \\
\hline $\begin{array}{l}\text { Contribution to } \\
\text { Production } \\
\text { Continuity }\end{array}$ & & & & \\
\hline Vendor Availability & & & & \\
\hline Ensuring Safety & $\square$ & & & \\
\hline $\begin{array}{l}\text { Consumption } \\
\text { Level }\end{array}$ & & & $\square$ & \\
\hline $\begin{array}{l}\text { Spare Parts Expire } \\
\text { Date }\end{array}$ & & & $\square$ & \\
\hline $\begin{array}{l}\text { Spare Parts } \\
\text { Inventory Cost }\end{array}$ & & & $\square$ & \\
\hline Maintenance Cost & & $\square$ & & \\
\hline $\begin{array}{l}\text { Spare Parts } \\
\text { Reliability }\end{array}$ & & $\square$ & & \\
\hline
\end{tabular}




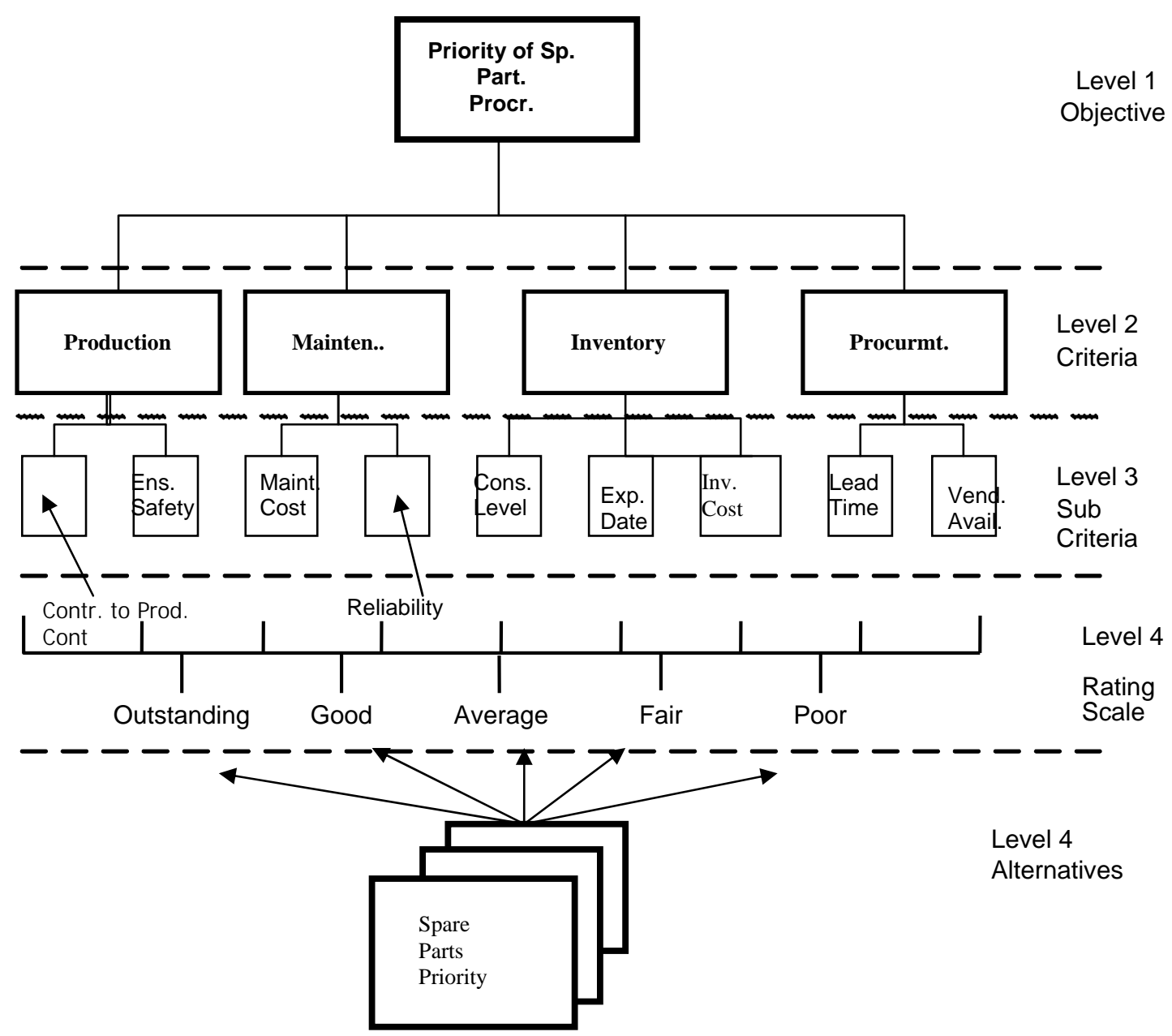

\section{Step 5: Weighting criteria}

Weighting criteria and sub-criteria uses usual AHP (Saaty 1980). So the detailed proces is not described in this part.

\section{Step 6: Weighting spare parts priority}

Weighting spare parts priority on the $4^{\text {th }}$ level is processed through rating scale technique as suggested by (Liberatore,1987). This level is different from the usual AHP approach in that a rating scale will be assigned to each sub criterion related to every alternative, instead of assessing pair wise comparison among the alternatives. The major advantage of this method is to overcome the explosion in the number of required comparisons when the number of alternatives is large $(n(n-1) / 2=190$ pair wise comparisons for each of the sub criteria if there are 20 alternatives). It is also very difficult to make pair wise comparisons among the spares part materials, because for a particular materials/spare parts, there are too many technical details. Thus, the use of the rating scale system can allow the evaluator to assign a rating to a spare part without making direct comparisons and thus avoiding time-consuming pair wise comparisons judgements. We have selected a 
five-points rating scale of outstanding (O), good (G), average (A), fair (F) and poor

(P) (Liberatore,1987).

The values reported in Tabell 2 have been chosen according to (Liberatore,1987). The local priory weights have been calculated by doing the geometric average of every values of each mark.

Tabel 2. Pair wise comparison judgment matrix for five-points rating scale.

\begin{tabular}{|l|l|l|l|l|l|c|}
\cline { 2 - 6 } \multicolumn{1}{c|}{} & $\mathrm{O}$ & $\mathrm{G}$ & $\mathrm{A}$ & $\mathrm{F}$ & $\mathrm{P}$ & Local priorities weights \\
\hline $\mathrm{O}$ & 1 & 3 & 5 & 7 & 9 & 0.513 \\
$\mathrm{G}$ & $1 / 3$ & 1 & 3 & 5 & 7 & 0.261 \\
$\mathrm{~A}$ & $1 / 5$ & $1 / 3$ & 1 & 3 & 5 & 0.129 \\
$\mathrm{~F}$ & $1 / 7$ & $1 / 5$ & $1 / 3$ & 1 & 3 & 0.063 \\
$\mathrm{P}$ & $1 / 9$ & $1 / 7$ & $1 / 5$ & $1 / 3$ & 1 & 0.034 \\
\hline
\end{tabular}

Meanwhile, contribution of the proposed research is: during evalution process, every evaluator has a specific and limited role in evaluating a spare part according to related criteria. For example, when a spare part is evaluated according to criteria "contribution to production continuity" and "ensuring safety", only evaluators who are member of operation function have authorization to evalute the spare part score. In fact, based on Tabel 1, the both criteria are related to operation function. By this way, the evaluation mechanism ensures that spare parts is evaluated by the right people who know exactly the spare part charateristics. In the same manner, when a spare part is evaluated according to criteria "spare part delivery lead time" and "vendor availability", only evaluators who are member of procurement function have authorization to evalute the spare part score, because the both criteria are related to procurement function.

Step 7: List spare parts procurement priority

Finally, the model can list priority of spare parts procurement. This list is a result of evaluation process based on relationship between ceriteria and associated functions. Cross functional conflicts can be compromized through identification decision criteria related to each function in conflict.

\section{Conclusion}

Use of the proposed model can compromize cross functional conflicts in spare parts procurement decision making process. Contribution of the proposed research is: during evalution process, every evaluator has a specific and limited role in evaluating a spare part according to related criteria. This mechanism helps decision maker in avoiding miss understanding about given criteria. Empirical experience of model implementation in five manufacturing companies has shown that every people from different functions are satisfied with decision concerning spare parts procurement priority.

The five-point rating scale of assessing large number of spare parts has contributed in accelerating spare parts evaluation process. In fact, to evaluate a great number of spare parts, the proposed model does not use pairwise comparisons judgements any more. The spare parts 
scoring process uses the five-point rating scale which does not consume much evaluation time.

By the aid of the proposed model, all decision makers can prioritize actions which are best fit to organizational needs, not to functional needs.

\section{References}

[Liberatore 1987] Liberatore M.J. "An extension of the analytic hierarchy process for industrial R\&D project selection and resource allocation” IEEE Transaction of Engineering Management 1987; EM-34(1): 12-8.

[Liberatore 1989] Liberatore M.J. “A decision support approach for R\&D project selection”. In: Golden B.L., Wasil E.A., Harker P.T., editors. The analytic hierarchy process applications and studies. New York: Springer, 1989. p 13-29.

[Saaty \& al. 1994] Saaty T.L., Vargas L.G., Decision making in economic, political, social, and technological environment with the analytic hierarchy process. Pittsburgh: RWS Publications, 1994.

[Suryadi, Kadarsah \& Sadewo Prasetyo, 2002], Kadarsah Suryadi \& Sadewo Prasetyo, "Perancangan Prototipe Sistem Pendukung Keputusan Pemenang Tender Telekomunikasi Dengan Menggunakan Metode Analytical Hierarchy Process (AHP)" Seminar INSAHP, Universitas Petra Surabaya, Indonesia, Nopember 2002.

[Suryadi, Kadarsah 2003],”Decision Model for “Material Stock vs non Stock” using combination of AHP and Cut off Point Method”, ISAHP, Bali, August, 2003

[Suryadi, Kadarsah 2005],"Planning and Developing a Web Based Group Decision Support System for Project Oriented Company Using Analytic Hierarchy Process”, ISAHP, Honolulu, July 8-10, 2005

[Tam \& al. 2001] Tam M.C.Y., Tummala V.M.R. "An application of the AHP in vendor selection of a telecommunications system” Omega 29 (2001) 171-182. 